\title{
Color and Phenolic Content Changes during Flower Development in Groundcover Rose
}

\author{
Valentina Schmitzer ${ }^{1}$, Robert Veberic, Gregor Osterc, and Franci Stampar \\ Biotechnical Faculty, Agronomy Department, Jamnikarjeva 101, SI-1000 Ljubljana, Slovenia
}

AdDitional INDEX wORDs. Rosa $\times$ hybrida, cultivars, stages, colorimetric parameters, $\mathrm{pH}$, phenolics

\begin{abstract}
In the present study, the chemical and morphological status of eight cultivars of groundcover rose (Rosa $\times$ hybrida) with a range of flower colors was investigated. From the methanolic extracts of rose petals collected from flowers at four developmental stages, several phenolic compounds were identified via high-performance liquid chromatography/mass spectrometry, including five anthocyanins, which are especially important for the visual attributes of rose flowers. Colorimetric parameters were also measured and correlated with total anthocyanins and cell sap pH levels. During flower development from bud to senescent stage, a significant trend was detected; lightness $\left(L^{*}\right)$ increased, $b^{*}$ decreased in all analyzed roses, and $a^{*}$ decreased in pink and red cultivars. Cell sap pH level increased from bud to senescent petals; fresh weight, dry weight, and water content increased to fully open stage and were then reduced in senescent petals. Total anthocyanin and quercetin content increased from bud stage to fully open flowers, and was decreased in senescent ones. However, the highest content of total phenolics was measured in buds and partially opened flowers, respectively. Three distinct groups were formed according to the content of total anthocyanins and quercetins; white cultivars were most distant from the red ones, which were similar to the pink and light red cultivars.
\end{abstract}

Groundcover rose is one of the most widely used roses in public spaces. Being relatively low maintenance, and having resistance to pests and diseases, winterhardiness, a long blooming period, and compact growth make them an ideal ornamental plant for parks as well as home gardens. A vast selection of different cultivars of Rosa Xhybrida with a color spectrum ranging from whites to intense purples is available.

Especially in red rose cultivars, a visible change in color during flower development and senescence is detected (Schmitzer et al., 2009). As the flower matures, different physiological, biochemical, and genetic processes occur in cells that contributes to the visual changes and characterizes a number of phases in flower life (Sood et al., 2006). In rose, it is common to observe several flower developmental stages on a single plant. Quite often, the intense color of rose buds changes to the subtle tones of fully opened flowers and the bluish hues of senescent petals. This phenomenon can be attributed to several factors: First, due to the changes in the content of various phenolic compounds and second, to an increase in cell sap pH level. Sood and Nagar (2003) and Sood et al. (2006) investigated the levels of acidic and bound phenols as well as total anthocyanins in rose petals and measured an increase in the initial stages of flower development, followed by a decrease at the fully open stage. However, in these studies on cut rose flowers, no data were reported on the content of phenolics in senescent rose petals. In contrast, a study of Barthe and Vaillant (1993) focused on postharvest changes in rose petal cell sap only from the partially open flower stage to late senescence, but no biochemical composition was determined. Thus, information about the relationship of individual anthocyanins to rose flower development stages is lacking.

Received for publication 19 Jan. 2010. Accepted for publication 15 Mar. 2010. This work is part of program Horticulture No. P4-0013-0481, funded by the Slovenian Research Agency (ARRS).

We would like to thank Arboretum Ljubljana for providing rose samples for the present study.

${ }^{1}$ Corresponding author. E-mail: valentina.schmitzer@bf.uni-lj.si.
The rose flower phenolic compounds, especially anthocyanic pigments, have been extensively studied, and considerable information about flower color biochemistry is available. Our past research on miniature rose flower development (Schmitzer et al., 2009) reported changes in individual phenolics at four developmental stages and correlated them to petal color modifications. However, only one cultivar was studied, and cellular changes in relation to phenolic composition during flower development were not monitored. The present work upgrades the insight into the biochemical composition of attached rose flowers during flower development from bud to full senescence with morphological and physiological changes in three different color groups of groundcover roses. Moreover, as the quantification of specific phenolics in groundcover cultivars of $R$. $\times$ hybrida is still scarce, the new information provides a valuable insight to the phenolic composition of selected cultivars, which can be interesting for potential breeding material.

\section{Materials and Methods}

Plant material. Eight cultivarss of $R$. $\times$ hybrida growing in Arboretum Ljubljana in Ljubljana, Slovenia (lat. $46.1^{\circ} \mathrm{N}$, long. $14.6^{\circ} \mathrm{E}, 250 \mathrm{~m}$ altitude), were selected for this study and flowers were sampled in the beginning of Aug. 2009. Flower petals of three white flowering cultivars (NOAschnee, KOReb, and Sea Foam), two pink flowering cultivars (The Fairy and KORverlandus), and three red flowering cultivars (POUleas, MORedfar, and Gärtnerfreude) were collected at four different flower developmental stages (Fig. 1) as described earlier (Schmitzer et al., 2009): 1) bud [B (ends of sepals separated, petal color intense, petals still closed)], 2) partially open flower [POF (outer whorls unfurled, half open flower), 3) fully open flower [FOF (petals fully unfurled, full bloom)], 4) senescent flower [SF (petals rolled outward, discoloration detected, and easily abscised flower)].

Petals from individual flowers were hand plucked at each developmental stage, packed into paper bags, and transported 


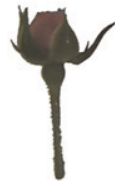

B

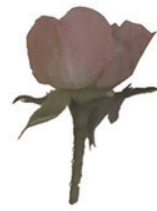

POF

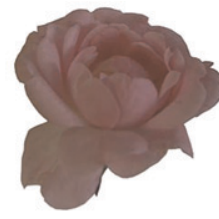

FOF

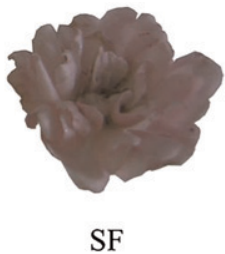

Fig. 1. Four stages of flower development in rose cultivar The Fairy: $\mathrm{B}=$ bud, $\mathrm{POF}=$ partially open flower, $\mathrm{FOF}=$ fully open flower, $\mathrm{SF}=$ senescent flower.

on ice to laboratory facilities, where they were immediately analyzed.

Petal color measurements. Flower color was measured by a portable colorimeter (CR-10 Chroma; Minolta, Osaka, Japan) with $\mathrm{C}$ illuminant. The colorimeter was calibrated with a white standard calibration plate before use. In CIE $L^{*} a^{*} b^{*}$ system of color representation, the $L^{*}$ value corresponds to a dark-bright scale and represents the relative lightness of colors with a range from 0 to $100(0=$ black, $100=$ white $)$. Color parameters $a^{*}$ and $b^{*}$ extend from -60 to $60 ; a^{*}$ negative is for green and $a^{*}$ positive is for red and $b^{*}$ negative is for blue and positive for yellow. The hue angle $\left(h^{\circ}\right)$ is expressed in degrees from 0 to 360 , where $0^{\circ}=$ red, $90^{\circ}=$ yellow, $180^{\circ}=$ green and $270^{\circ}=$ blue. Color was measured in the middle of each petal (three replicates per flower; five flowers per stage) to ensure equal measurement conditions.

Fresh WEIGHT (FW), DRY WEIGHT (DW), AND WATER CONTENT DETERMinATION. Fresh weight of petals was recorded immediately after harvest. Petal water content was determined as the percentage of total petal weight $[(\mathrm{FW}-\mathrm{DW}) / \mathrm{FW} \times 100]$ by weighing samples of all petals from a single flower at four developmental stages. Petal DW was recorded after drying at $105^{\circ} \mathrm{C}$ for $48 \mathrm{~h}$ in an electrical oven until constant weight was obtained. Five replicates per developmental stage were taken.

PH MEASUREMENTS. Relative changes in cell sap pH (correlating to changes in vacuolar $\mathrm{pH}$ ) were determined by extracting $0.5 \mathrm{~g}$ of macerated petals in $5 \mathrm{~mL}$ of bidistilled water. After $2 \mathrm{~h}$ and occasional stirring, $\mathrm{pH}$ of the solution was measured with a $\mathrm{pH}$ meter (S20 SevenEasy ${ }^{\mathrm{TM}}$; Mettler Toledo, Columbus, $\mathrm{OH})$. Each measurement was repeated on five individual flowers per developmental stage.

EXTRACTION AND HIGH-PERFORMANCE LIQUID CHROMATOGRAPHY (HPLC) DETERMINATION OF PHENOLIC COMPOUNDS. Fresh petals of individual flowers were ground to a fine powder with liquid nitrogen and $0.5 \mathrm{~g}$ of powder was extracted with $2 \mathrm{~mL}$ of methanol containing 3\% (v/v) formic acid and 1\% (w/v) 2,6-Di-tert-butyl-4-methylphenol (BHT) in an ultrasonic bath for $1 \mathrm{~h}$. Samples were centrifuged for $7 \mathrm{~min}$ at $12,000 g_{\mathrm{n}}$. Supernatant was filtered through Chromafil AO-45/ 25 polyamide filter (Macherey-Nagel, Düren, Germany) and was transferred to a vial before injection in a HPLC system. Samples were analyzed using a Thermo Finnigan Surveyor HPLC system (Thermo Scientific, San Jose, CA) with a diode array detector at $350 \mathrm{~nm}$ (quercetins) and $530 \mathrm{~nm}$ (anthocyanins). An HPLC column $(150 \times 4.6 \mathrm{~mm}$, Gemini $3 \mu \mathrm{C} 18$; Phenomenex, Torrance, CA), protected with a Phenomenex security guard column operated at $25{ }^{\circ} \mathrm{C}$, was used. The injection volume was $20 \mu \mathrm{L}$ and the flow rate was maintained at $1 \mathrm{~mL} \cdot \mathrm{min}^{-1}$. The elution solvents were aqueous $1 \%$ formic acid (A) and 99.8\% acetonitrile (B). Samples were eluted according to the linear gradient described by Marks et al.
(2007): 0 to $5 \mathrm{~min}, 3 \%$ to $9 \% \mathrm{~B} ; 5$ to $15 \mathrm{~min}, 9 \%$ to $16 \% \mathrm{~B} ; 15$ to $45 \mathrm{~min}, 16 \%$ to $50 \% \mathrm{~B}$; 45 to $50 \mathrm{~min}, 50 \%$ isocratic; and finally washing and reconditioning of the column. The concentrations of phenolic compounds were assessed from peak areas and were quantified with the use of corresponding external standards and anthocyanins by the use of a calibration curve of cyanidin-3,5-di-O-glucoside. Anthocyanins were further identified using a mass spectrometer (LCQ Deca XP MAX, Thermo Scientific) with an electroscopy interface (ESI) operating in positive ion mode using $\mathrm{MS}^{2}$ scanning mode from $\mathrm{m} / \mathrm{z} 115$ to 800. The injection volume was $10 \mu \mathrm{L}$ and the flow rate was maintained at $1 \mathrm{~mL} \cdot \mathrm{min}^{-1}$. Capillary temperature was $250{ }^{\circ} \mathrm{C}$, the sheath gas and auxiliary gas were 20 and 8 units respectively, the capillary voltage was $26 \mathrm{~V}$, and the spray voltage was $4 \mathrm{~V}$. Total anthocyanins and total quercetins were calculated as the sum of all identified anthocyanins and quercetins, respectively. All compounds were expressed as micrograms per gram DW.

Determination of TOTAL PHenOlic CONTENT. Extraction of petal samples for determining total phenolics was done as described above, but without the addition of BHT. The total phenolic content (TPC) was determined using the FolinCiocalteau phenol reagent method (Singleton and Rossi, 1965). To $100 \mu \mathrm{L}$ of extract [diluted $1: 8(\mathrm{v} / \mathrm{v})$ with $\mathrm{MeOH}$ ], $6 \mathrm{~mL}$ of bidistilled water and $500 \mu \mathrm{L}$ of Folin-Ciocalteau reagent were added; after resting between $8 \mathrm{~s}$ and $8 \mathrm{~min}$ at room temperature, $1.5 \mathrm{~mL}$ of sodium carbonate $(20 \% \mathrm{w} / \mathrm{v})$ was added. The extracts were mixed and left in an oven for 30 min at $40{ }^{\circ} \mathrm{C}$ before measuring absorbance on a spectrometer (ultraviolet/VIS Lambada Bio 20; Perkin Elmer, Waltham, MA) at $765 \mathrm{~nm}$. A mixture of bidistilled water and reagent was used as blank. The TPC was expressed as gallic acid equivalents (GAE) milligrams per gram DW.

Chemicals. The standards used to determine the phenolic compounds in samples were quercetin-3-O-rutinoside and cyanin chloride from Sigma-Aldrich (Steinheim, Germany), and quercetin-3-glucoside, quercetin-3-xyloside, quercetin-3-arabinoside, quercetin-3-galactoside, and quercetin-3-rhamnoside from Fluka (Buchs, Switzerland). For the total phenolic content, FolinCiocalteu's reagent, sodium carbonate, gallic acid, and ethanol from Sigma were used. The chemicals for the sample preparation and mobile phases were methanol, BHT, and acetonitrile from Sigma-Aldrich and formic acid from Fluka. The water used in mobile phase was bidistilled and purified with a Milli-Q water purification system by Millipore (Bedford, MA).

Statistical ANALYsis. The results were analyzed using the Statgraphics Plus 4.0 (Manugistics, Rockville, MD) program using one-way analysis of variance. Differences in phenolic concentrations among developmental stages were estimated with Duncan's multiple range test $(P<0.05)$. Multiple-variable analysis with Pearson's correlation coefficient (r) was calculated between color variable $b^{*}$ and cell sap $\mathrm{pH}$ level and between color variable $a^{*}$ and total anthocyanin content at $P<$ 0.05. Multivariate statistical analysis (hierarchical cluster analysis, discriminate analysis, and classification) was conducted to interpret the differences in total anthocyanins and total quercetins among color groups.

\section{Results and Discussion}

Petal color measurements. White cultivars were all characterized by negative values for parameter $a^{*}$ and higher 
values for parameters $b^{*}$ and $h^{\circ}$, compared with pink and red cultivars (Table 1). Parameter $a^{*}$ is associated with the amount of red coloration present in rose petals (Biolley and Jay, 1993), and our results show a clear increase from light pink cultivar The Fairy to intense red cultivars Gärtnerfreude and MORedfar. In pink and red cultivars, color parameter $a^{*}$ declined at the successive stages of flower development, with statistically lowest values measured on senescent petals, except in cultivar MORedfar. This shift also corresponds well with the gradation in red color from buds to senescent flowers in red/pink cultivars. A postharvest study of Marousky and Carlyle (1985) on rose cultivar Better Times reported a decline in parameter $a^{*}$ after $3 \mathrm{~d}$ of vase life, however, petals of the other two red cultivars studied did not show the same gradation in this color value. Similarly, in our study on white cultivars, no significant neg- ative tendency in value $a^{*}$ was detected, which can be explained by a low content of red pigments even at the initial phases of flower development. A steady decrease in value $b^{*}$ was observed in all analyzed cultivars; the blue hues in the final stage of senescence became apparent, particularly in red cultivars. The petals faded to a bluish color, consistent with the reports of Itzhaki et al. (1990) on 'Mercedes' rose, where they visually assessed the color change in late senescence, but no colorimetric measurements were reported. The high degree of bluing in red rose petals held in water or preservative is in part due to the increase in $\mathrm{pH}$ caused by an increase in free ammonia. Higher $\mathrm{pH}$ levels cause structural modification in anthocyanic pigments, resulting in their blue color (Asen et al., 1971) expressed by a decrease of the $b^{*}$ value. With the progression of flower development, lightness $\left(L^{*}\right)$ was increased

Table 1. Colorimetric parameters of petals at four flower stages and eight cultivars of Rosa $\times$ hybrida.

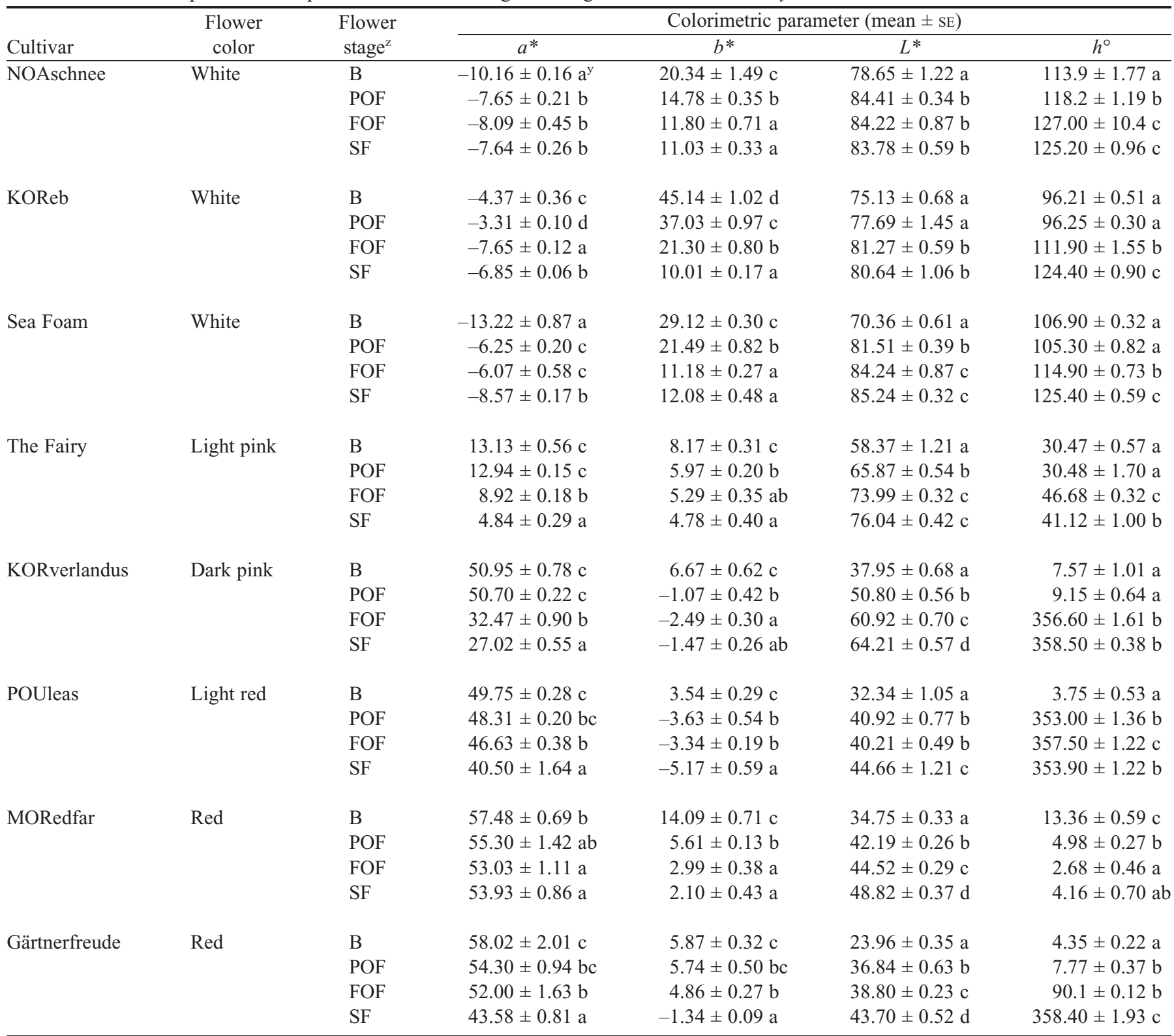

${ }^{\mathrm{z}} \mathrm{B}=$ bud, $\mathrm{POF}=$ partially open flower, $\mathrm{FOF}=$ fully open flower, $\mathrm{SF}=$ senescent flower.

${ }^{y}$ Different letters $(\mathrm{a}-\mathrm{d})$ in rows of individual cultivars denote statistically significant differences in colorimetric parameters by Duncan's multiple range test at $P<0.05$ among flower developmental stages. 
in all rose cultivars as flower petals visually became paler (Table 1). Similar changes in colorimetric parameters were described in a previous study on a red rose cultivar KORcrisett (Schmitzer et al., 2009) and cut 'Mercedes' rose flowers (OrenShamir et al., 2001) where the paler flower color, described with the parameter $L^{*}$, was also most evident. This could be due to an increase in water content and the dilution effect as well as lower content of specific pigments in some cultivars (Table 2, Figs. 3 and 5), respectively.

Fresh WEIGHT, DRY WEIGHT, AND WATER CONTENT. The mean FW, DW, and water content of petals in all eight cultivars generally increased from bud to fully open flower. The highest values of FW were measured at POF or FOF stage, and a decrease in $\mathrm{FW}$ was observed at the senescent stage of flower development in all cultivars except in 'MORedfar' (Fig. 2A). Similar results were reported for Rosa damascena and Rosa bourboniana flowers in the study of Sood et al. (2006), where FW of petals reached its maximum at fully open stage, but no measurements were taken at senescence. An increase in FW can be attributed to a high percentage of water content in enlarged cells of POF and FOF in most cultivars analyzed (Fig. 2D), suggesting that cell expansion and particularly water accumulation in vacuoles play an important role in the rose flower development. Petal DW increased from buds to partially or fully opened flowers and was again reduced in senescent flowers, except for cultivars KOReb and Sea Foam (Fig. 2B). Similarly, water content increased from bud to subsequent developmental stages, with the highest percentage measured in

Table 2. Anthocyanins in petals of eight cultivars of Rosa $\times$ hybrida at four flower developmental stages.

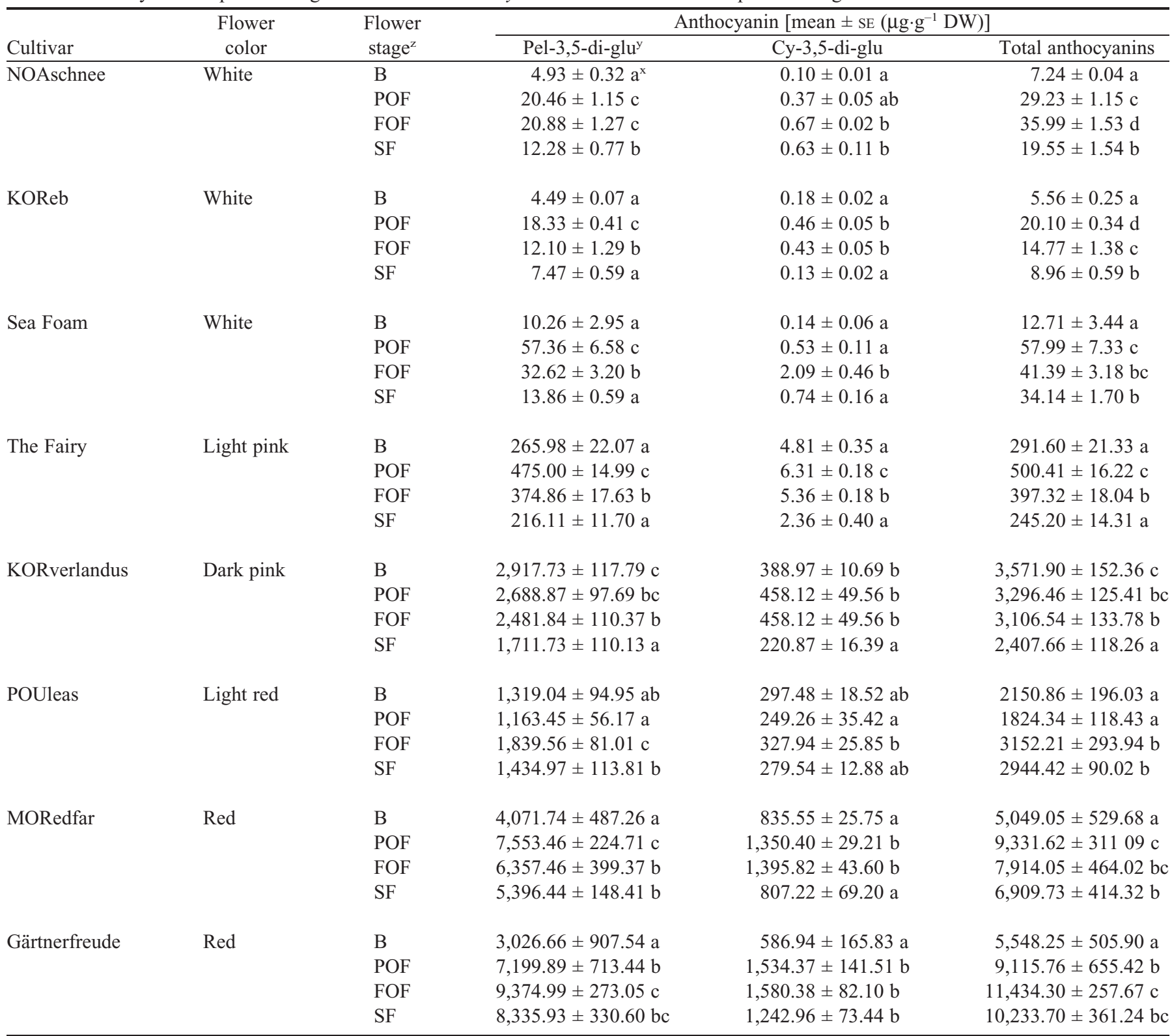

${ }^{\mathrm{z}} \mathrm{B}=$ bud, $\mathrm{POF}=$ partially open flower, $\mathrm{FOF}=$ fully open flower, $\mathrm{SF}=$ senescent flower.

${ }^{y}$ Pel-3,5-di-glu = pelargonidin-3,5-di-O-glucoside, Cy-3,5-di-glu = cyanidin-3,5-di-O-glucoside.

'Different letters $(\mathrm{a}-\mathrm{d})$ in rows of individual cultivars denote statistically significant differences in individual and total anthocyanins by Duncan's multiple range test at $P<0.05$ among flower developmental stages. 

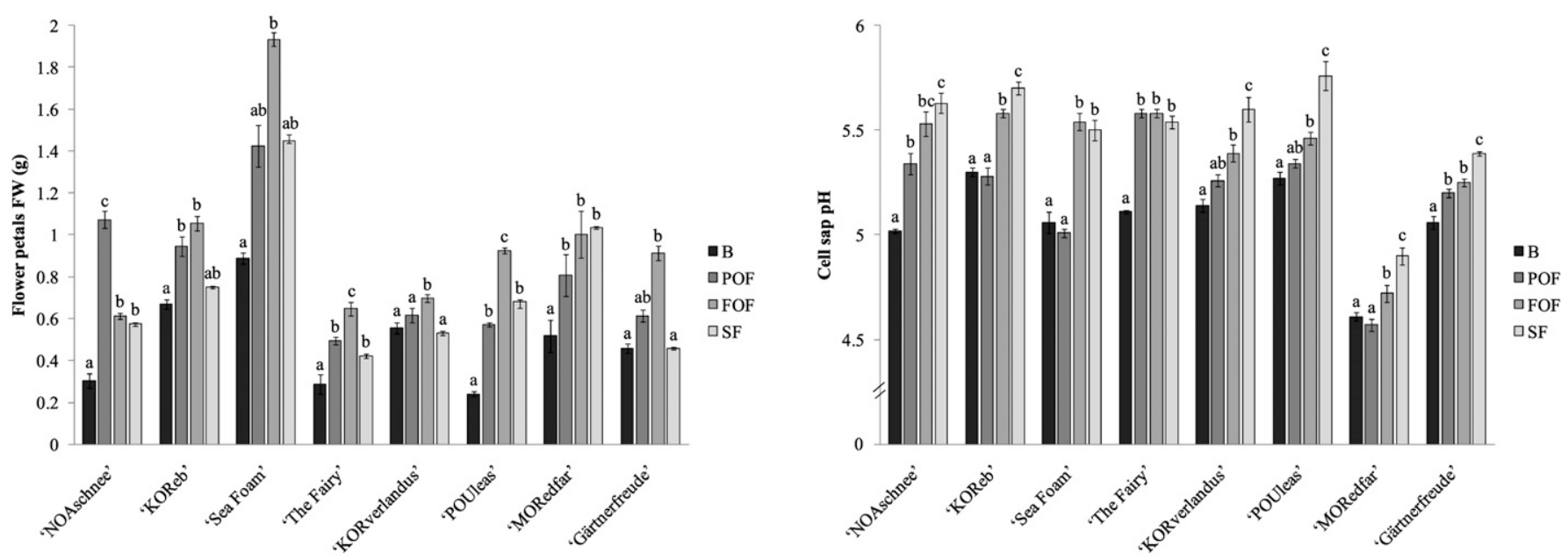

B

$\mathrm{D}$
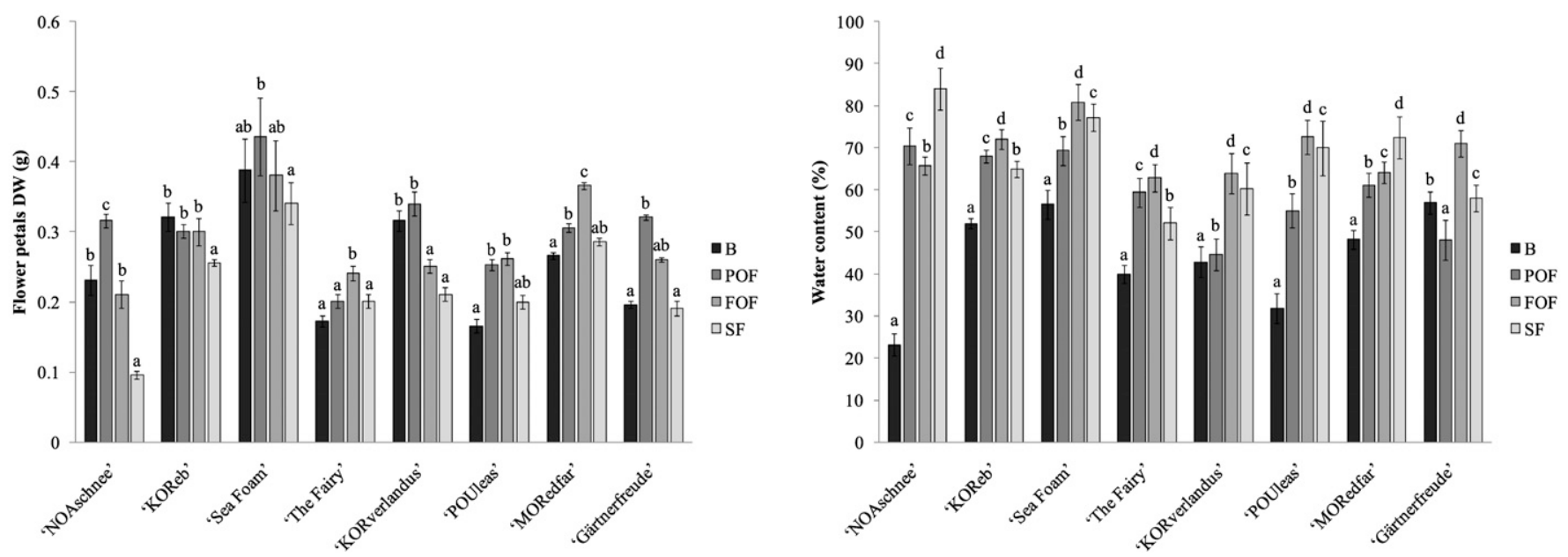

Fig. 2. Flower petal fresh weight $(\mathbf{A})$, dry weight $(\mathbf{B})$, cell sap pH level $(\mathbf{C})$, and petal water content $(\mathbf{D})$ at four flower stages $(\mathrm{B}=$ bud, $\mathrm{POF}=$ partially open flower, $\mathrm{FOF}=$ fully open flower, $\mathrm{SF}=$ senescent flower) and eight cultivars of Rosa $\times$ hybrida. Different letters (a-d) denote statistically significant differences in parameters by Duncan's multiple range test at $P<0.05$ among flower developmental stages of individual cultivars.

fully open flower stage and a slight drop in senescent petals (Fig. 2D) with the exception of 'NOAschnee', 'Gärtnerfreude', and 'MORedfar'. This is in accordance with the results of van Doorn and Schroder (1995) who state that petals of various rose cultivars were completely turgid or partially desiccated when shed. The relationship between relatively a high percentage of water in senescent petals and statistically lower values of fresh weight could be explained with two processes. The structural decomposition of the cell wall with a direct impact on cell wall yield was previously described in carnation petals (De Vetten and Huber, 1990). Also, in smaller part, it could be connected with a lower synthesis of secondary metabolites, and a higher breakdown and consequently a decrease in total phenolic content measured in the final stages of rose petal senescence (Fig. 3).

PH MEASUREMENTS. Generally, a weakly acidic vacuolar $\mathrm{pH}$ is most often maintained in plant cells and the slightest modifications often lead to changes in anthocyanin stability and, consequently, tissue color (Tanaka et al., 2005). In all analyzed cultivars, cell sap $\mathrm{pH}$ level of developing flowers increased from bud to senescent stage, respectively (Fig. 2C). Similarly, in cut 'Mercedes' and 'Sweet Promise' rose, cell sap $\mathrm{pH}$ increased with aging of petals during vase life (Barthe and Vaillant, 1993; Oren-Shamir et al., 2001). The high degree of postharvest bluing in rose petals can be linked to the increase in $\mathrm{pH}$ level (Asen et al., 1971). Aging petals of cut roses rapidly increase in ammonia, due to the proteolysis, resulting in an increase of cell sap $\mathrm{pH}$, which is one of the physiological processes accompanying senescence (Kuiper et al., 1996).

The well-known bluing phenomenon in senescing red roses is tightly linked to it as studies describe a shift into the blue range of some anthocyanins when $\mathrm{pH}$ is increased. Asen et al. (1971) reported that cyanidin-3,5-di-O-glucoside was colorless at lower $\mathrm{pH}$ levels and formed complexes with quercetin derivates when $\mathrm{pH}$ was increased. These complexes can modify the color of the plant tissue to bluish hues. Although visually no blue coloration was apparent in senescent petals of white 
cultivars, a similar increase of $\mathrm{pH}$ level was also measured in their cell sap. Interestingly, a tight correlation coefficient was calculated between the $b^{*}$ value and cell sap $\mathrm{pH}$ values for all analyzed cultivars, including white ones (Table 3). Previous research on postharvest stages of rose reported similar correlation between cell sap $\mathrm{pH}$ and $b^{*}$ value, however, only a single red rose cultivar was analyzed (Oren-Shamir et al., 2001).

Phenolic composition. As reported previously (Biolley et al., 1994; Mikanagi et al., 1995; Schmitzer et al., 2009), two predominant anthocyanic pigments are present in rose petals, namely pelargonidin-3,5-di-O-glucoside and cyanidin3,5-di-O-glucoside (Table 2). Anthocyanins were detected in all analyzed roses, including white cultivars. Rose petals also contained small amounts of cyanidin-3-O-glucoside, pelargonidin-3O-glucoside, and peonidin-3-O-glucoside (data not shown); however, the latter was not detected in white cultivars. Gen-

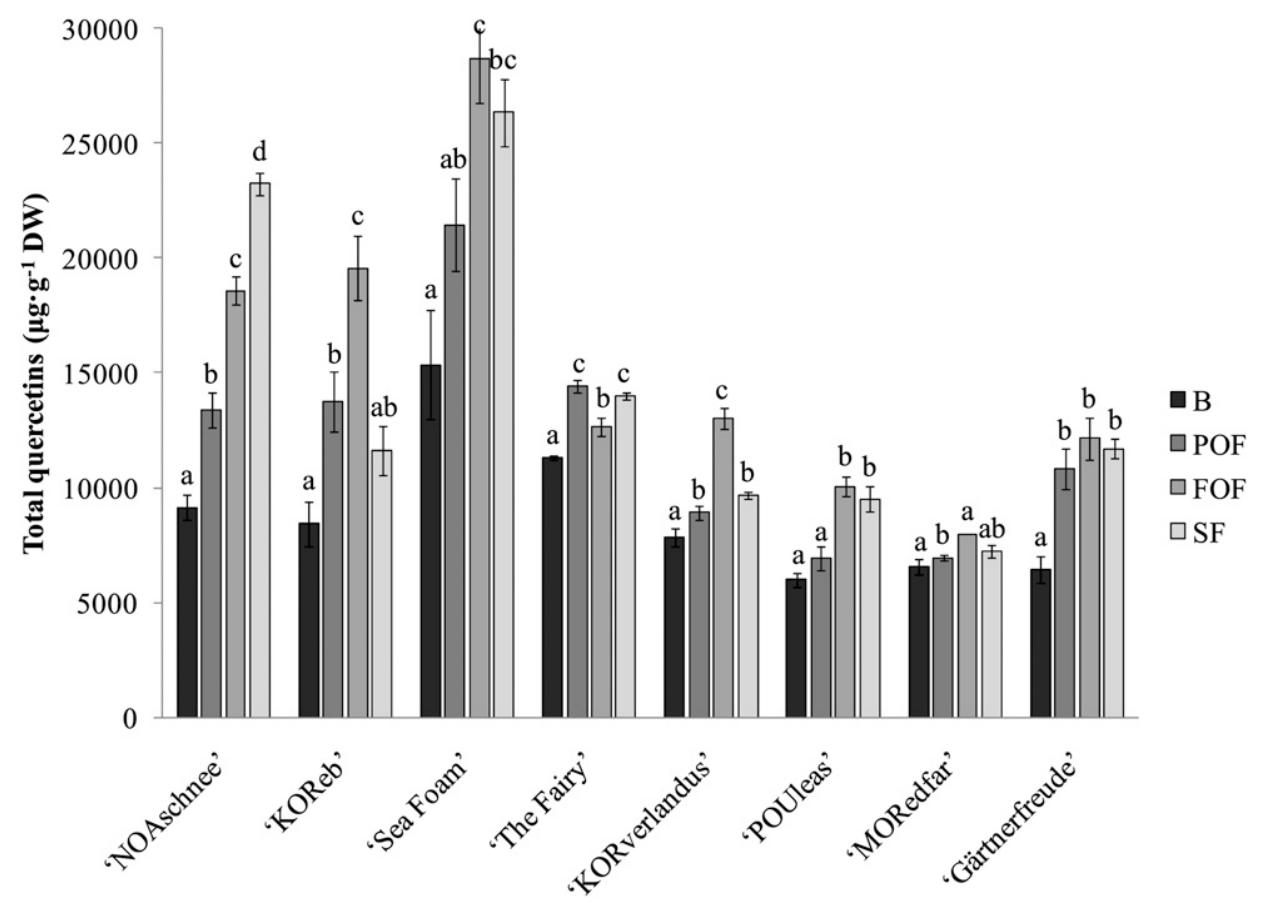

Fig. 3. Total quercetins in petals of eight cultivars of Rosa $\times$ hybrida at four flower developmental stages $(\mathrm{B}=\mathrm{bud}$, $\mathrm{POF}=$ partially open flower, FOF $=$ fully open flower, $\mathrm{SF}=$ senescent flower $).$ Different letters $(\mathrm{a}-\mathrm{d})$ denote statistically significant differences in total quercetins by Duncan's multiple range test at $P<0.05$ among flower developmental stages of individual cultivars.

Table 3. Pearson's correlation coefficients between different colorimetric parameters and cell sap pH level or total anthocyanins (fresh weight) for eight cultivars of Rosa $\times$ hybrida.

\begin{tabular}{lcc}
\hline Cultivar & $b^{* / \text { cell sap pH }}$ & $\begin{array}{c}\text { Correlation coefficient } \\
\text { of } a^{*} / \text { total anthocyanins }\end{array}$ \\
\hline NOAschnee & $-0.80^{* * * z}$ & $0.58^{*}$ \\
KOReb & $-0.96^{* * *}$ & $0.77^{* *}$ \\
Sea Foam & $-0.79^{* * *}$ & $0.61^{*}$ \\
The Fairy & $-0.71^{* *}$ & $0.84 * *$ \\
KORvelandus & $-0.76^{* *}$ & $0.83^{* * *}$ \\
POUleas & $-0.73^{* *}$ & $0.92^{* * *}$ \\
MORedfar & $-0.76^{* *}$ & $0.82^{* * *}$ \\
Gärtnerfreude & $-0.89^{* * *}$ & $0.74 *$
\end{tabular}

zPearson's correlation coefficients with statistical significance of the estimated correlations presented at $* P<0.05, * * P<0.01$ and $* * * P<0.001$. erally, during flower development, the content of total and major anthocyanins increased from bud to fully open flower and dropped slightly at the senescent stage (Table 2). This custivers, although it mechanism of anthocyanin turnover in analyzed cultivars is airly similar. However, Sood et al. (2006) spectrometrically entuated total anthocyanin content in flowers of $R$. damascena followed by a decrease in the half and opened flowers, with no data presented for senescent there is no universal trend of anthocylevel declines fas cyanin degradation occurs in different plant organs due to a variety of environmental and developmental conditions; the latter can be linked to the vacuolar changes that decrease the stability of the pigments and cause chemical degradation or increased vulnerability to degrading enzymes (such as peroxidases and $\beta$-glucosidases) present in the vacuoles (Oren-Shamir, 2009). Increased $\mathrm{pH}$ level of the vacuolar sap in senescing petals of rose flowers (Fig. 2C) may have a negative effect on the stability of the anthocyanins and cause significant chemical degradation of the pigments. Moreover, as in the research on the fading color of petunia petals (Oren-Shamir, 2009), the altered vacuolar $\mathrm{pH}$ resulted in a modification of anthocyanin structure, which can also be linked to the fading and bluing of the senescent petals of red and pink rose cultivars.

A tight correlation was obtained between total anthocyanin content (FW) and color value $a^{*}$ for all analyzed cultivars (Table 3 ), similar to the reports of Schmitzer et al. (2009), where only one red cultivar was studied. Although no apparent visual change in the coloration of white cultivars during flower development was detected, a correlation between anthocyanin content and color value $a^{*}$ revealed a similar relationship to that of the red or pink cultivars analyzed. The content of cyanidin-3,5-di-O-glucoside can be related to blue coloration in red and pink cultivars at later stages of flower development when $\mathrm{pH}$ increases (Asen et al., 1971). However, in white cultivars, containing much lower amounts of cyanidin3,5-di-O-glucoside, no blue hues were visually apparent, even in the late senescence stage. It seems that cyanidin-3,5-di-O-glucoside plays 
an important role in color modification as the content of this pigment is as much as 1000-fold higher in red cultivars and they all exhibit petal bluing.

Six flavonols, belonging to the group of quercetins (Q), were identified in all cultivars, Q-3-rutinoside, Q-3-galactoside, Q-3glucoside, Q-3-xyloside, Q-3-arabinoside, and Q-3-rhamnoside (data not presented), previously reported in several rose cultivars (Asen, 1982). The predominant Q-3-ramnoside and Q-3-glucoside comprised more than $90 \%$ of total quercetin content (TQC), respectively. TQC was always lowest in rose buds; a significant increase was detected in subsequent developmental stages. In 'NOAschnee', 'The Fairy', 'POUleas', and 'Gärtnerfreude', statistically highest TQC was measured in senescent petals (Fig. 3). Three distinct groups were formed when comparing the content of total anthocyanins and quercetins in eight cultivars (Fig. 4). White cultivars (NOAschnee,

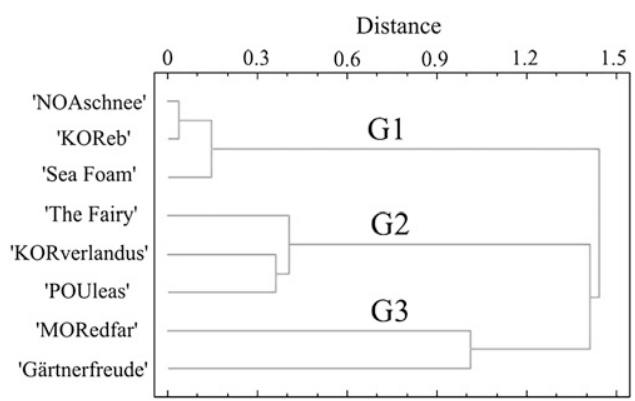

Fig. 4. Dendrogram of eight cultivars of Rosa $\times$ hybrida using ward method based on square Euclidian distance from biochemical data (total anthocyanins and total quercetins). G1 to G3 represent different groups.
KOReb, and Sea Foam) fit in the first group, which was statistically most distant from the group of red cultivars (MORedfar and Gärtnerfreude). Two other pink and a light red cultivar (The Fairy, KORverlandus, and POUleas) were closer to the red color group.

In comparison with other rose species, all analyzed cultivars of $R$. $\times$ hybrida contained similar amounts of total phenolics (Fig. 5) on a dry weight basis. Kumar et al. (2009) reported TPC for $R$. damascena to be $145 \mathrm{mg} \cdot \mathrm{g}^{-1} \mathrm{FW}$ GAE, $178 \mathrm{mg} \cdot \mathrm{g}^{-1} \mathrm{FW}$ GAE for $R$. bourboniana, and as much as $254 \mathrm{mg} \cdot \mathrm{g}^{-1} \mathrm{FW}$ GAE for Rosa brunonii. However, Cai et al. (2005) report $189 \mathrm{mg} \cdot \mathrm{g}^{-1}$ DW GAE for Rosa chinensis. The highest content of total phenolics was measured in buds or partially open flower stage, respectively. Phenolics play an important role in antioxidant defense by the peroxidase/phenolic/ascorbate system and the decline in these compounds make senescent flowers more vulnerable to oxidative stress (Takahama and Oniki, 1997). With the exception of 'Gärtnerfreude', all other cultivars had a low content of phenolics at the late senescence stage, suggesting that petals are more susceptible to oxidation leading to cell death in the final developmental stages.

According to Kumar et al. (2008), the flower is considered a strong sink of assimilates and the corolla continues to import dry matter throughout its development. But in the final stages of senescence, membrane destruction, electrolyte leakage, and a decrease in total protein (Sood et al., 2006) results in a decrease in petal dry and fresh weight. In the present study, the similarity of the developmental turnover in secondary metabolites among different cultivars of groundcover rose is established. The petal accumulates total and specific phenolics until full bloom stage, followed by a decrease in senescence. These mechanisms could be used in the selection of flower stages with highest values of secondary metabolites important for the pigment or confectionary industry. A detailed study on different rose species and cultivars is needed to describe these processes and further elucidate the individual phenolic turnover during flower development.

\section{Literature Cited}

Asen, S. 1982. Identification of flavonoid chemical markers in roses and their high pressure liquid chromatographic resolution and quantification for cultivar identification. J. Amer. Soc. Hort. Sci. 107:744-750.

Asen, S., K.H. Norris, and R.N. Stewart. 1971. Effect of $\mathrm{pH}$ and concentration of the anthocyanin-flavanol co-pigment complex on the color of 'Better Times' roses. J. Amer. Soc. Hort. Sci. 96:770-773.

Barthe, P. and V. Vaillant. 1993. Changes in the buffering capacity of cell sap in senescing rose petals. Scientia Hort. 54:165-174.

Biolley, J.P. and M. Jay. 1993. Anthocyanins in modern roses: Chemical and colorimetric features in relation to the color range. J. Expt. Bot. 44:1725-1734.
Fig. 5. Total phenolic content (TPC) in petals of eight cultivars of Rosa $\times$ hybrida at four flower developmental stages $(\mathrm{B}=$ bud, $\mathrm{POF}=$ partially open flower, $\mathrm{FOF}=$ fully open flower, $\mathrm{SF}=$ senescent flower). Different letters (a-c) denote statistically significant differences in TPC by Duncan's multiple range test at $P<0.05$ among flower developmental stages of individual cultivars. 
Biolley, J.P., M. Jay, and M.R. Viricel. 1994. Flavonoid diversity and metabolism in 100 Rosa $\times$ hybrida cultivars. Phytochemistry 35:413-419.

Cai, Y.Z., J. Xing, M. Sun, Z.Q. Zhan, and H. Corke. 2005. Phenolic antioxidants (hydrolysable tannins, flavonols, and anthocyanins) identified by LC-ESI-MS and MALDI-QIT-TOF MS from Rosa chinensis flowers. J. Agr. Food Chem. 53:9940-9948.

De Vetten, N.C. and D.J. Huber. 1990. Cell wall changes during the expansion and senescence of carnation (Dianthus caryophyllus) petals. Plant Physiol. 78:447-454.

Itzhaki, H., A. Borochov, and S. Mayak. 1990. Age-related-changes in petal membranes from attached and detached rose flowers. Plant Physiol. 94:1233-1236.

Kuiper, D., H.S. van Reenen, and S.A. Ribot. 1996. Characterisation of flower bud opening in roses: A comparison of Madelon and Sonia roses. Postharvest Biol. Technol. 9:75-86.

Kumar, N., G.C. Srivastava, and K. Dixit. 2008. Flower bud opening and senescence in roses (Rosa hybrida L.). 2008. Plant Growth Regulat. 55:81-99.

Kumar, N., P. Bhandari, B. Singh, and S.S. Bari. 2009. Antioxidant activity and ultra-performance LC-electrospray ionization-quadrupole time-of-flight mass spectrometry for phenolics-based fingerprinting of rose species: Rosa damascena, Rosa bourboniana and Rosa bruninii. Food Chem. Toxicol. 47:361-367.

Marks, S.C., W. Mullen, and A. Crozier. 2007. Flavonoid and chlorogenic acid profiles of English cider apples. J. Sci. Food Agr. 87:719-728.

Marousky, F.J. and T.C. Carlyle. 1985. Postharvest color changes in red rose petals. Proc. Florida State Hort. Soc. 98:137-139.
Mikanagi, Y., M. Yokoi, Y. Ueda, and N. Saito. 1995. Flower flavonol and anthocyanin distribution in subgenus Rosa. Biochem. Syst. Ecol. 23:183-200.

Oren-Shamir, M. 2009. Does anthocyanin degradation play a significant role in determining pigment concentration in plants? Plant Sci. 177:310-316

Oren-Shamir, M., G. Dela, R. Ovadia, A. Nissim-Levi, S. PhilosophHadas, and S. Meir. 2001. Differentiation between petal blueing and senescence of cut 'Mercedes' rose flowers. J. Hort. Sci. Biotechnol. 76:195-200.

Schmitzer, V., R. Veberic, G. Osterc, and F. Stampar. 2009. Changes in the phenolic concentration during flower development of rose 'KORcrisett'. J. Amer. Soc. Hort. Sci. 134:491-496.

Singleton, V.L. and J.A. Rossi. 1965. Colorimetry of total phenolics with phosphomolybdic-phospoholungistic acid reagents. Amer. J. Enol. Viticult. 16:144-158.

Sood, S. and P.K. Nagar. 2003. Changes in abscisic acid and phenols during flower development in two diverse species of rose. Acta Physiol. Plant. 25:411-416.

Sood, S., D. Vyas, and P.K. Nagar. 2006. Physiological and biochemical studies during flower development in two rose species. Scientia Hort. 108:390-396.

Takahama, U. and T. Oniki. 1997. A peroxidase/phenolics/ascorbate system can scavenge hydrogen peroxide in plant cells. Physiol. Plant. 101:845-852.

Tanaka, Y., Y. Katsumoto, F. Brugliera, and J. Mason. 2005. Genetic engineering in floriculture. Plant Cell Tissue Organ Cult. 80:1-24.

van Doorn, W.G. and C. Schroder. 1995. The abscission of rose petals. Ann. Bot. (Lond.) 76:539-544. 